Scientił studia, São Paulo, v. 10, n. 3, p. 535-60, 2012

\title{
st \\ O legado de Thomas Kuhn após cinquenta anos
}

\author{
André Luis de Oliveira Mendonça \\ 电
}

RESUMO

Neste artigo, analiso o pensamento de Thomas Kuhn à luz da ideia de que sua obra desencadeou um processo de rediscussão acerca das relações entre ciência e sociedade. De fato, A estrutura das revoluções científicas, publicado em 1962, causou um impacto que deixou marcas indeléveis nos debates arrolados sobre a prática científica. Dois efeitos colaterais decorreram desse acontecimento: um possibilitou o surgimento - talvez a concretização de uma tendência - de questões extremamente técnicas e, em alguma medida, estéreis; o outro acirrou os ânimos da querela acerca do lugar que a ciência ocupa, ou deveria ocupar, na sociedade. $\mathrm{O}$ argumento central desenvolvido neste artigo é o de que o segundo efeito foi engendrado por Kuhn de forma inconsciente. Em outras palavras, Kuhn pode ser visto como tendo propiciado uma liberação involuntária, no sentido de ter recolocado o debate em torno da interface entre a ciência e a sociedade, embora a sua revelia. Dessa forma, ele pode ser apontado como a grande fonte de inspiração para o programa forte e os subsequentes science studies. É necessário, portanto, uma reavaliação das suas teses principais, a fim de que se possa lançar luz sobre a questão da interação entre os fatores racionais e os valores sociais.

PalaVras-Ghave • Ciência. Sociedade. Fatores racionais. Valores sociais. Kuhn. Programa forte. Science studies.

\section{INTRODUÇÃO: A LIBERAÇÃO INVOLUNTÁRIA}

Sem correr o risco de estar exagerando, Kuhn se tornou a figura, senão mais influente, ao menos mais debatida na filosofia da ciência anglófona da segunda metade do século xx. A grande quantidade de trabalhos sobre ele que, nos últimos anos, continua sendo publicada é um forte indício da atualidade de suas ideias, bem como da influência duradoura de sua obra. Seu livro, A estrutura das revoluções científicas (1978 [1962]), que completa 50 anos, é o maior best-seller da história da epistemologia, tendo causado uma verdadeira "revolução" nas questões filosóficas referentes à ciência. O êxito editorial e acadêmico dessa obra impôs-lhe, no entanto, um preço a pagar. No âmbito da filosofia, Kuhn não produziu praticamente nada de novo desde então, uma vez que se sentiu obrigado a dispender grande parte de seu tempo tentando, por um lado, amainar as 
críticas que lhe foram endereçadas e, por outro lado, rechaçar grande parte das recepções laudatórias. Para ser mais correto, Kuhn reformulou alguns pontos de sua explanação original, alterando a forma de argumentação, mas sem deixar de tratar e de defender suas velhas teses. Sendo assim, não é muito difícil inteirar-se do seu pensamento filosófico acerca da ciência, pelo menos no que tange aos problemas aqui em questão; embora tais problemas em si, ainda que poucos, levem-nos a enveredar por caminhos bastante espinhosos.

Kuhn é frequentemente apresentado pelos comentadores como um autor diretamente envolvido, juntamente com Stephen Toulmin, Imre Lakatos e Paul Feyerabend, entre outros, na formulação de uma nova concepção de ciência contraposta àquela defendida pelo positivismo lógico, como se tivesse sido responsável por uma "mudança de paradigma” na epistemologia anglo-saxã. ${ }^{1}$ Costuma-se destacar, sobretudo, o fato de Kuhn ter atribuído um papel epistemológico relevante à história, e não meramente ilustrativo, na sua reconstrução da racionalidade científica. Outros pontos de discordância em relação aos positivistas lógicos são normalmente postos em relevo, a saber, a lógica da ciência não seria indutivista, o método científico não seria um critério de demarcação suficiente, a metafísica não seria necessariamente nociva à ciência. Todos esses tópicos teriam levado Kuhn a produzir uma nova imagem de ciência. Não obstante esse tipo de interpretação ainda ser predominante, é cada vez mais frequente atenuar a virada que Kuhn e seus colegas teriam propiciado. Alguns autores dirão que a chamada nova filosofia da ciência ou filosofia histórica da ciência é apenas uma das faces da mesma moeda, sendo a outra a tradição positivista, visto que Kuhn ainda continua concebendo a ciência de forma unificada, com a única diferença de uma mera inversão de ênfase da observação e do experimento para a teoria (cf. Rouse, 1996). ${ }^{2}$

1 Aqui, evidentemente, o conceito de paradigma está sendo tomado em seu sentido "metacientífico", como já vem ocorrendo. De fato, até mesmo no contexto filosófico mais amplo, o termo tem começado a ser crescentemente empregado. Normalmente, a despeito das nuances e diferenças entre si, a conotação comum subjacente aos distintos usos aponta na direção de um modelo ou padrão a ser seguido como referencial teórico norteador. Por exemplo, Habermas (2002) divide a história da filosofia em três grandes paradigmas: do ser (predominante na filosofia antiga e medieval), da consciência (predominante na filosofia moderna) e da linguagem (predominante na filosofia contemporânea).

2 Há um movimento que poderíamos denominar revisionista do positivismo lógico que procura mostrar certa continuidade das ideias de Kuhn em relação aos positivistas lógicos, como se a filosofia historicamente orientada de Kuhn não tivesse representado uma grande novidade. Na verdade, esses autores empreendem uma revisão, não das próprias posições positivistas, e sim das críticas dirigidas a essa perspectiva. O argumento básico pode ser assim resumido. O positivismo lógico foi muito mal interpretado e, além disso, suas principais teses anteciparam as defendidas pelos então denominados "novos filósofos da ciência" (por exemplo, Kuhn). Comparativamente ao que veio depois, tais teses teriam sido defendidas de modo ainda mais consistente e plausível. Michael Friedman, um dos expoentes desse movimento, acredita que sem esse tipo de revisão não poderemos recolocar a história filosófica recente em seus verdadeiros trilhos (cf. Friedman, 1999). O projeto de Friedman é bastante amplo em seu escopo, 
Aqui, o meu objetivo consiste em analisar criticamente a reconstrução da ciência levada a cabo por Kuhn, de modo a apreender a forma como ele articula o distanciamento - embora dando margem a uma reaproximação - entre os domínios social e científico. Para tanto, abordo, de início, os dois momentos considerados por Kuhn como cruciais da atividade científica: a ciência normal e a revolução científica. Em seguida, deter-me-ei na questão do papel desempenhado pela história da ciência na obra de Kuhn com o fito de desnudar sua verdadeira concepção acerca do lugar ocupado pela ciência na sociedade. Por fim, eu foco na relação (repulsiva) que Kuhn manteve com os defensores do programa forte, o que comprovará o fato de ele não ter tido, inicialmente, uma percepção clara dos desdobramentos de suas teses originárias.

\section{A GiÊnCIA NORMAL E SEUS GRíticos}

Nitidamente, ocorreu uma assimetria na recepção e na avaliação da reconstrução da ciência empreendida por Kuhn. Apesar de ter concebido o desenvolvimento científico nos termos de uma tensão essencial entre o normal e o revolucionário, esse último aspecto foi o que recebeu maior atenção. Entretanto, para elaborar o argumento de que o intento de Kuhn era defender a autonomia e a independência da ciência, faz-se estrategicamente pertinente abordar também a modalidade científica que ele denominou de ciência normal.

Na explanação kuhniana, a ciência normal forma um binômio indissociável com o paradigma. A ciência entra em uma fase normal justamente quando é guiada sob a égide de um paradigma. Nas palavras de Kuhn "ciência normal" significa a pesquisa firmemente baseada em uma ou mais realizações científicas passadas [paradigmas]. Essas realizações são reconhecidas durante algum tempo por alguma comunidade científica específica como proporcionando os fundamentos para a sua prática posterior" (1978 [1962], p. 29). Além disso, essas realizações científicas desempenham o papel de um exemplar, sentido primevo e etimológico de paradigma.

Em função das críticas de polissemia (cf. Mastermann, 1979), equivocidade (cf. Shapere, 1984), entre outras, dirigidas ao conceito de paradigma, Kuhn (1989) procurou em diversas ocasiões responder a elas, chegando mesmo a substituir o termo pela

pois pretende diminuir o fosso que há entre a filosofia analítica americana e a filosofia continental, partindo do pressuposto de que ambas possuem o mesmo background filosófico, a saber, o neokantismo. A partir de um fato histórico (um seminário ocorrido em Davos), Friedman (2000) sustenta que Carnap e Heidegger, respectivamente representantes dessas vertentes filosóficas, mostraram ser ambos tributários do neokantismo, ainda que o tenham utilizado para fins distintos. Seja como for, a figura central desse "encontro histórico", para o argumento de Friedman, é Cassirer, autor mais conciliatório do ponto de vista epistemológico, e mais cosmopolita do ponto de vista político. 
expressão "matriz disciplinar", composta por quatro elementos principais: exemplares, generalizações simbólicas, modelos e valores. Em seus últimos trabalhos, é comum encontrar o uso do termo "léxico".

Os paradigmas, ou exemplares, propiciam o advento do consenso - visível nas revistas especializadas, bem como nos manuais de ensino - acerca dos fundamentos da prática científica. Sob sua posse, cessam os debates de ordem metodológica (quais os meios adequados de investigação), de ordem epistemológica (o que deve ser investigado e quais soluções devem ser alcançadas) e de ordem ontológica (qual a natureza das entidades investigadas). Uma vez findadas essas discussões basilares, os cientistas podem despender seu tempo em questões mais específicas. Já se configura, aqui, uma das características marcantes da ciência, para a qual Kuhn chama a atenção sem, porém, emitir sua avaliação a respeito, a saber, a especialização.

A rigor, a atividade levada a cabo pela ciência dita normal consiste no aperfeiçoamento das questões relacionadas aos três referidos domínios. Além disso, essa modalidade de ciência ocupa-se com o que Kuhn denominou "operações de limpeza", isto é, o trabalho de depuração das persistentes inconsistências do paradigma.

Poucos dos que não trabalham realmente com uma ciência amadurecida dão-se conta de quanto trabalho de limpeza desse tipo resta por fazer depois do estabelecimento do paradigma ou de quão fascinante é a execução desse trabalho. Esses pontos precisam ser bem compreendidos. A maioria dos cientistas, durante toda a sua carreira, ocupa-se com operações de limpeza. Elas constituem o que chamo de ciência. Examinado de perto, seja historicamente, seja no laboratório contemporâneo, esse empreendimento parece ser uma tentativa de forçar a natureza a encaixar-se dentro dos limites preestabelecidos e relativamente inflexíveis fornecidos pelo paradigma" (Kuhn, 1978, p. 44,-5).

Desse modo, os cientistas objetivam aprofundar-se no conhecimento dos fatos pré-selecionados pelo paradigma, ${ }^{3}$ melhorar a correlação entre esses fatos e o paradigma, articular ainda mais o próprio paradigma. Pode-se resumir tudo isso em uma única frase, a tarefa da ciência normal consiste em realizar a "promessa de sucesso" feita pelo paradigma. Ora, isso soa como uma situação na qual o que se dá é, no fundo, sempre mais do mesmo, uma vez que tudo já foi, de algum modo, previsto pelo paradigma, qualquer novidade, seja a invenção de uma teoria, seja a descoberta de um fato, deve ser ignorada de modo a garantir a subsistência da ciência normal.

30 grifo é tão-somente para indicar que a conotação atribuída por Kuhn à palavra "fato” difere daquela presente na tradição realista. Já a tradição analítica prefere utilizar a palavra "dado" a "fato". Haja vista a famosa expressão cunhada por Sellars (1997), "o mito do dado". 
A normalidade científica ocorre quando a pesquisa é conduzida sob a forma de resolução de quebra-cabeças. Kuhn descontentou alguns filósofos, e também alguns cientistas, ao afirmar que a motivação desses últimos não é a busca da verdade, mas sim solucionar puzzles, isto é, mostrar habilidade para tornar o aparentemente anômalo (o que poderia ser visto como um contraexemplo do paradigma) em um problema solúvel à luz do paradigma vigente. Caso haja cientistas que não deem conta dos problemas abordados, o fracasso será atribuído a eles próprios, dada a confiança que se nutre a respeito do paradigma. É como se o paradigma exercesse uma função na ciência semelhante ao que o dogma desempenharia na religião (aliás, um dos títulos dos trabalhos iniciais de Kuhn (1979) é justamente "A função do dogma na investigação científica”).

A ciência descrita por Kuhn como sendo normal é sinônimo de pesquisa especializada. Segundo Kuhn, a especialização é a condição para o progresso científico. O paradigma restringe drasticamente os fatos a serem levados em conta por uma dada comunidade científica, permitindo, desse modo, que se possa aprofundar o conhecimento a seu respeito. Com o passar do tempo, a relevância dada por Kuhn à especialização na obtenção do progresso científico foi ficando cada vez mais explícita; de todo modo, essa imbricação já aparece em A estrutura.

O pressuposto fundamental da ideia de especialização concebida por Kuhn é o de haver consenso, que, por sua vez, remonta ao conceito de paradigma. Como se disse, o paradigma instaura a concordância em torno das questões fundamentais a serem tratadas, de modo que não se torna necessário discutir quais fatos devem ser investigados, quais métodos devem ser empregados, nem quais soluções devem ser encontradas. Esse consenso é o grande responsável pelo avanço na solução dos problemas. Um desiderato do conhecimento científico do qual Kuhn não abriu mão foi a noção de progresso. Como a maioria dos filósofos e historiadores de seu tempo, Kuhn partia do princípio de que o progresso - apesar de não ser, no seu caso, necessariamente cumulativo - é uma diferença específica da ciência face a outras formas de conhecimento. Tanto que suas reconstruções são, grosso modo, sempre uma tentativa de exibir como a ciência progride, seja no sentido normal de acumulação, seja no sentido revolucionário de ruptura. (Só esse fato já torna patente que ele não almejou minar a autoridade cultural exercida pela ciência, como alguns imaginam.) $\mathrm{O}$ consenso seria justamente o que assegura a possibilidade de crescimento do conhecimento científico.

O progresso científico, no sentido de aprofundamento no conhecimento dos fatos, de aperfeiçoamento dos métodos de investigação e avanço nos resultados esperados é uma decorrência do consenso engendrado pelo paradigma. Nesse sentido, podese afirmar que, durante a ciência normal, o conhecimento progride de forma linear e cumulativa. Esse aspecto da descrição kuhniana não é tão frequentemente discutido; às vezes, ele não é sequer notado, o que não ocorre com a sua concepção descontinuísta 
de progresso concernente às revoluções científicas. O que está sendo sugerido é que o progresso, em termos kuhnianos, se dá de duas formas distintas e complementares: o progresso contínuo ocorre durante a ciência dita normal e o progresso não cumulativo eclode por ocasião das revoluções científicas (cf. Mendonça, 2003).

A ideia de uma ciência normal aos moldes de Kuhn sofreu críticas bastante contundentes. Popper (1979, p. 66) proferiu: "só posso dizer que vejo um grande perigo nisso [a suposta atitude dogmática da ciência normal] e na possibilidade que tem de tornar-se normal (assim como vejo um grande perigo no aumento da especialização, outro fato histórico inegável): um perigo para a ciência e, na verdade, para nossa civilização", no que foi acompanhado por Watkins (1979). Feyerabend (1979, p. 247-8), com seu conhecido estilo incisivo e provocativo, foi além. "Pois tudo indica que o crime organizado é a solução de enigmas par excellence. Todo enunciado feito por Kuhn a respeito da ciência normal permanece verdadeiro quando substituímos 'ciência normal' por 'crime organizado'; e todo enunciado que ele escreve acerca do 'cientista' individual aplica-se com a mesma força, digamos, ao arrombador de cofres individual". Kuhn se esquivava, alegando que estaria apenas sendo descritivo. Ora, como ele mesmo já indicara em A estrutura das revoluções científicas, os níveis descritivo e prescritivo são praticamente inextricáveis; logo, sua reconstrução de como as coisas se passam na ciência implicaria também, em certo sentido, como elas devem acontecer. Concordando, em parte, com essas avaliações, eu penso que a ciência normal parece perder de vista uma característica salutar do conhecimento científico, e mesmo de outras formas de saber, como a filosofia, ou seja, a atitude crítica, entendida em seu significado mais comum de não aceitação passiva na recepção de algo, seja a transmissão de conhecimento, seja a de valores.

É claro que a noção de consenso considerada por Kuhn como a base do progresso científico não significa a ausência de divergências pontuais, ou seja, para que haja ciência normal, não é preciso que os cientistas pensem sempre da mesma forma. Não obstante, as questões acerca dos fundamentos são vistas como pontos pacíficos, sendo passíveis apenas de aperfeiçoamento. A rigor, para Kuhn, o acordo sobre os fundamentos é o que distingue a ciência como uma forma bem-sucedida de conhecimento das demais formas. Por ter como guia um paradigma, a ciência não precisaria mais de despender tempo em "vãs discussões” e, como consequência, poderia realizar a sua tarefa mais normal: lograr progresso. 4 Daí, não ser equivocado extrair-se a conclusão

$4 \mathrm{O}$ mais irônico é que, embora dirigido às ciências naturais, basicamente à física, o relato de Kuhn obteve uma recepção mais favorável justamente nas humanidades, especialmente nas ciências sociais. Muitos cientistas sociais e das humanidades em geral sentiram-se encorajados a procurar paradigmas em seus respectivos domínios de atuação, pois isso significaria a legitimidade de reputá-los como científicos e progressivos. Minhot (2003), por exemplo, leva a cabo a tarefa de pensar a psicanálise freudiana a partir da noção kuhniana de matriz disciplinar. No con- 
de Kuhn estar fazendo, ainda que sub-repticiamente, uma recomendação, a meu ver, indesejável ao cientista: "se pretendes contribuir com o progresso científico, torna-te a-crítico e deixa de pensar filosoficamente". Julgo que isso impõe o falso dilema de ter de se escolher entre o aprofundamento do conhecimento e a discussão reflexiva, uma vez que ambos podem - e até mesmo devem - andar juntos.

Kuhn (1978 [1962]) equiparou a discussão crítica e reflexiva acerca dos fundamentos à filosofia. $\mathrm{O}$ recurso a essa última seria necessário apenas quando não vige o consenso. A filosofia seria uma espécie de remédio para os momentos de anormalidade. Fazendo justiça a Kuhn, devemos lembrar que a separação entre a filosofia e a ciência é apregoada ou, quiçá, constatada, desde o advento da ciência moderna. De qualquer forma, ainda que a filosofia enquanto disciplina autônoma não possa ser utilizada normalmente pela ciência - assunto que é assaz controverso -, a postura crítica e a capacidade reflexiva costumam, em tese, acompanhar integralmente os cientistas, ao menos os do período histórico narrado por ele, que é sobretudo o da formação da ciência moderna. Mesmo se o relato de Kuhn correspondesse aos fatos, isto é, se a ciência fosse normal no sentido por ele narrado, poder-se-ia dizer que algo estaria errado. Afinal, julgo que a crítica, em seu sentido mais difundido de contraponto ao pensamento vigente ou estabelecido, é que é sinônimo de progresso, na medida em que possibilita mudar o estado atual das coisas, sempre que preciso for.

\section{A revolução Gientífici e Seus descontentes}

Kuhn (1978 [1962], p. 125), ao discorrer sobre as revoluções científicas ("episódios de desenvolvimento não-cumulativo, nos quais um paradigma mais antigo é total ou parcialmente substituído por um novo, incompatível com o anterior"), pretendia chamar a atenção para o outro lado da moeda da racionalidade e do progresso científico. O que ele não imaginava era toda a celeuma que isso despertaria. Ao enfraquecer, aparentemente, o papel dos argumentos na decisão entre paradigmas rivais, a maioria dos intérpretes julgou que Kuhn estaria defendendo que a irracionalidade impera na ciência. Se não há espaço para a "força do argumento", abre-se o flanco para o predomínio do "argumento da força”, costuma-se pensar. O próprio Kuhn não almejou pôr a questão em termos tão dramáticos. De todo modo, o fato é que ele fez afirmações bastante polêmicas - mais do que isso, estabeleceu analogias inusuais até então - e depois passou grande parte do tempo tentando justificar-se.

texto brasileiro, por exemplo, o relato de Kuhn foi incorporado por diversas áreas fora do domínio das ciências naturais mais tradicionais, como física, química e biologia: desde a epidemiologia (cf. Mello Filho, 1997) até a psiquiatria (cf. Chibeni \& Almeida, 2007). 
Por julgar que as controvérsias entre paradigmas oponentes não poderiam ser decididas de maneira normal, Kuhn (1978 [1962]) comparou a revolução científica às experiências da psicologiagestalt, à revolução política, à conversão religiosa, para mencionar as mais extremadas. Não é difícil inferir que essas analogias suscitaram - por que não dizer? - certa ira em alguns defensores da prática científica, entendida como "o paradigma da racionalidade". Afinal, como os filósofos analíticos da ciência poderiam admitir que o seu objeto de estudo fosse igualado à política e à religião, esferas tidas como do domínio da decisão e da crença respectivamente, e não da evidência e/ou da demonstração (peculiaridades do conhecimento científico)?

Das escassas recepções favoráveis advindas de filósofos formados no interior da tradição analítica, uma digna de menção foi a de Rorty ${ }^{5}$ que, inclusive, qualificou entusiasticamente Kuhn de

um grande filósofo (...). Penso que filósofo é a descrição mais apropriada para alguém que remapeia a cultura - que sugere um modo novo e promissor para pensarmos a respeito das relações entre as várias grandes áreas da atividade humana (1998, p. 21).

Consoante Rorty (1994), Kuhn teria contribuído sobremaneira para atenuar as fronteiras de demarcação entre o científico e os demais domínios. Estendendo o conceito de ciência normal ao restante da cultura como um todo, Rorty (1994) advoga a tese de que termos como "racionalidade" e "objetividade" são menos uma questão de correspondência com a realidade dos fatos do que de concordância entre os sujeitos cognoscentes.

Assim, o "discurso normal" não seria um "privilégio" da ciência, mas pode ser encontrado em todas as áreas da cultura em que impere o consenso. Em outras palavras, é possível que haja uma literatura e uma política racionais e objetivas, para citar apenas dois exemplos, assim como a física newtoniana é objetiva e racional. Dito de forma mais direta, Rorty deu boas-vindas à obra de Kuhn, porquanto ela teria ajudado a minar a autoridade e a superioridade epistêmicas da ciência. ${ }^{\mathbf{6}}$

5 Há também os que, como Doppelt (1978), defenderam o suposto relativismo epistemológico sustentado por Kuhn. 6 Apesar de ter saudado Kuhn, Rorty defendeu a superioridade moral da ciência como se a comunidade científica não fosse mais objetiva e racional do que as outras esferas da cultura, e sim mais solidária e mais justa. Segundo ele, "os cientistas naturais têm sido freqüentemente exemplares conspícuos de certas virtudes morais. Os cientistas são merecidamente famosos por apoiarem-se antes na persuasão do que na força, pela (relativa) incorruptibilidade, pela paciência e caráter razoável. A Sociedade Real e o círculo de libertins érudits reuniram, no século xvir, uma classe de pessoas moralmente melhores do que aquela que estava no seio da Oxford ou da Sorbonne daquele tempo. Mesmo hoje, são eleitas para a Sociedade Real pessoas mais honestas, imparciais e confiáveis do que, por exemplo, para a Câmara dos Comuns. Na América, a Academia Nacional de Ciências é notoriamente menos corruptível do que a 
Cabe a ressalva de que Kuhn procurou analisar única e exclusivamente a esfera científica, sem aparentemente nenhuma pretensão de que sua descrição extrapolasse às demais esferas. Ele jamais se pronunciou, a não ser de forma circunstanciada, a respeito de problemas fora do domínio da ciência; de modo que é mais apropriado "vêlo" como filósofo da ciência e historiador da ciência do que como "um grande filósofo", a despeito da artificialidade dessas divisões. Outros filósofos de sua geração, apesar de terem desenvolvido o pensamento a partir do viés da ciência, não deixaram de abordar as questões da cultura e da sociedade em sentido mais amplo (como Feyerabend, Toulmin e Lakatos, por exemplo).

Colocando de lado a questão do mérito da qualificação de Kuhn como um grande filósofo feita por Rorty, o fato é que $A$ estrutura propiciou um debate acalorado que, em certa medida, permanece vivo. Não constitui exagero afirmar que Kuhn determinou a agenda da filosofia da ciência na segunda metade do século xx. Dentre as controvérsias suscitadas por ele, nenhuma ocupou tanto destaque quanto a tese da incomensurabilidade. ${ }^{7}$

Faz-se oportuno percorrer, ainda que a passos largos, o itinerário de Kuhn nesse domínio específico. Para antecipar o que está em jogo, vale lembrar que seu objetivo foi combinar incomensurabilidade e progresso científico como ampliação de conhecimento. A propósito, em seus últimos trabalhos, Kuhn parece sugerir o seguinte tipo de declaração de espanto: "como posso ser considerado um irracionalista, se a minha tese da incomensurabilidade é a condição sine qua non para que surja o mais belo produto da racionalidade, o progresso científico?"

A despeito de ter concebido a incomensurabilidade como uma condição indispensável para o progresso científico, a verdade é que a tese foi geralmente vista como uma grande ameaça à racionalidade da ciência. Não era para menos, uma vez que em uma de suas primeiras formulações Kuhn afirmou:

Na escolha de um paradigma - como nas revoluções políticas - não existe critério superior ao consentimento da comunidade relevante. Para descobrir como as revoluções científicas são produzidas, teremos, portanto, que examinar não apenas o impacto da natureza e da lógica, mas igualmente as técnicas de argumenta-

\footnotetext{
Câmara dos Deputados" (Rorty, 1997, p. 86-7). O que Rorty deseja é defender o modo de vida americano (american way of life) sem precisar recorrer a fundamentações metafísicas. Para ele, a democracia liberal é superior a outras formas de organização política, ainda que não se possa prová-lo por meio de argumentos filósoficos (cf. Rorty, 1997, especialmente cap. 11).

7 Há diversos trabalhos sobre a tese da incomensurabilidade. Serão referidos alguns ao longo deste subitem. O que é importante ressaltar é o fato de a mencionada tese ter sido quase sempre identificada como sinônimo de relativismo, a despeito dos protestos persistentes de Kuhn.
} 
ção persuasiva que são eficazes no interior dos grupos muito especiais que constituem a comunidade dos cientistas (1978 [1962], p. 128).

Nessa passagem, torna-se patente que o desfecho das revoluções científicas não é determinado por critérios estritamente lógico-empíricos em seu sentido clássico. Em outras palavras, não se pode recorrer à correspondência com os fatos nem à coerência interna da teoria, de modo a decidir acerca de um conflito entre paradigmas. Isso porque um paradigma é incomensurável com outro. Abrir-se-ia espaço também para a retórica, cuja pertinência, tradicionalmente, foi atribuída a outros domínios, onde não se pode lidar com evidências. E mais: uma vez que os argumentos, seja de ordem lógica, seja de ordem empírica, não possuem força suficiente para decidir uma controvérsia científica, parece surgir espaço para que a "força" (entenda-se, aqui, o Estado, a política, os grupos sociais etc.) predomine. Estranhamente, Kuhn não se pronuncia a esse respeito. Ele apenas admite que essas esferas externas à ciência podem atuar diretamente sobre ela nesses episódios especiais de revoluções científicas, sem aprofundar a questão. De qualquer forma, por admitir que em caso de revoluções científicas a ciência normal não pode ser a última palavra, Kuhn sugere que fatores nãocientíficos podem entrar em ação. Ou seja, a ciência pode deixar de ser um assunto somente de cientistas nas oportunidades em que ela pára de funcionar normalmente (cf. Kuhn, 1978, p. 14-5).

Segundo Kuhn, os "fatos" não podem ser o tribunal das disputas científicas por serem moldados pelos paradigmas. A rigor, não existe fato puro, uma vez que toda observação está carregada de teoria. Assim como outros filósofos da ciência, Kuhn não aceitou a distinção entre termos observacionais e termos teóricos. Por essa razão, esse tipo de abordagem também é conhecido pela expressão "filosofia da ciência dominada pela teoria". Sem querer entrar nesse mérito, a questão é que o conceito de "paradigma" não é sinônimo de teoria. Sua carga semântica, ao menos em sua acepção inicial, parece ser bem mais rica. Ademais, a racionalidade testabilista comum aos positivistas lógicos e a Popper foi posta em xeque por Kuhn e pelos demais representantes da nova filosofia da ciência. As chamadas experiências cruciais não passariam de idealizações da genuína atividade científica. 8

Para evitar a pecha de relativista/irracionalista, mesmo sem admitir a possibilidade do recurso a algoritmos neutros, Kuhn (1989) ressaltou a atuação de critérios epistêmicos na escolha entre teorias. Ele elencou cinco desses critérios, reconhecendo que já teriam sido ressaltados pela própria filosofia da ciência tradicional como sendo os mais importantes na formulação de boas teorias científicas. São eles: exatidão, con- 
sistência, alcance, simplicidade e fecundidade. Eles não funcionam como regras matemáticas, mas como valores; ou seja, apesar de garantirem a objetividade da ciência, eles são aplicados de forma subjetiva. Isso porque

quando os cientistas têm de escolher entre teorias rivais, dois homens comprometidos completamente com a mesma lista de critérios para escolha podem, contudo, chegar a conclusões diferentes. Talvez interpretem a simplicidade de maneira diferente ou tenham convicções diferentes sobre o âmbito de campos em que o critério de consistência se deva aplicar. Ou talvez concordem sobre estas matérias, mas difiram quanto aos pesos relativos a ser acordados a estes ou a outros critérios, quando vários deles se desenvolvem em conjunto. No que respeita a divergências deste gênero, nenhum conjunto de critérios já proposto é útil (Kuhn, 1989, p. 388).

Mas não apenas a aplicação individual dos valores varia - a importância atribuída a eles também se modifica com o tempo e/ou de uma área para outra. Seja como for, apesar de admitir o peso que as preferências pessoais, por assim dizer, costumam exercer nas escolhas teóricas, Kuhn lança mão dos critérios epistêmicos padronizados de modo a defender a objetividade e a racionalidade da ciência. A única concessão que ele não faz aos filósofos tradicionais é a respeito da possibilidade de se encontrar ou descobrir um fundamento neutro. A decisão acerca de paradigmas é sempre determinada, não apenas por razões subjetivas, mas também por um referencial teórico prévio (outro sentido para o paradigma).

Tendo sofisticado a discussão sobre a atuação de valores na ciência, Lacey (2008; 2010) desenvolve o argumento central segundo o qual deveríamos traçar uma distinção entre valores sociais e valores epistêmicos, pois, mesmo a ciência contemporânea (veja-se, por exemplo, o caso dos transgênicos) não desfrutando mais de autonomia (sua agenda é pautada em função dos interesses comerciais do mercado) e nem de neutralidade (seus resultados servem exclusivamente a objetivos particulares), ela ainda costuma ser imparcial (a escolha de fatos e teorias e a proposta acerca da relação entre ambos são conduzidas sob os auspícios dos valores epistêmicos internos à própria ciência). Lacey defende, dentre outras teses interessantes, a ideia de que devemos recuperar o ideário da ciência moderna, com seus respectivos valores: além da manutenção da ainda intacta imparcialidade, devemos resgatar a genuína neutralidade (a aplicação da ciência não deve estar comprometida com interesses de grupos específicos, e sim com o bem-estar humano e ecológico em geral) e autonomia (as linhas de pesquisa devem ser livremente escolhidas pelos cientistas, sem perder de vista, obviamente, a função social da ciência). 
Por ter concebido os fatos científicos como emoldurados pelo paradigma, Kuhn afirmou que, durante uma revolução científica, "o mundo muda": um fato que era interpretado de uma forma passa a ser visto de outra. Obviamente, com o decorrer do tempo, ele foi procurando atenuar esse tipo de declaração. Talvez, aqui, Kuhn ainda estivesse concebendo as revoluções científicas muito mais em termos de mudanças de objetos de investigação, o que ele abandonaria depois. De fato, Kuhn começou a pressupô-las cada vez mais como surgimento de novas comunidades científicas do que de novos temas compartilhados. É o que já se constata no posfácio à segunda edição de A estrutura. Perceber essa guinada é fundamental para compreender a influência que ele exerceu sobre a sociologia do conhecimento científico. ${ }^{9}$

Outrosssim, Kuhn reformulou ou explicitou as características das revoluções científicas que permaneceram obtusas em suas primeiras versões. Kuhn (2000) destacou três aspectos que acompanham, inevitavelmente, as mudanças científicas. O primeiro diz respeito ao holismo teórico: os termos e/ou sentenças ganham seu significado dentro da teoria. Isso implica que uma alteração em um tópico específico de uma teoria acarreta uma revolução no todo. $\mathrm{O}$ segundo aspecto concerne à relação entre linguagem e mundo: em sua concepção de inspiração idealista (alhures fica evidente a influência também do pragmatismo), Kuhn defende que as mudanças revolucionárias não alteram apenas o critério de emprego dos termos ao mundo, mas também os próprios objetos e situações aos quais tais termos se aplicam. Por último, Kuhn afirma que, por ocasião das revoluções científicas, as metáforas e as analogias são descartadas, ou melhor, substituídas (cf. Kuhn, 2000).

Retomando mais propriamente o tema da incomensurabilidade (obviamente, esta é indissociável do tópico das revoluções científicas, sendo a minha divisão um mero artifício de argumentação), apesar de tê-la formulado como ausência de critérios estritamente lógicos e empíricos, Kuhn não aceitou as associações com o relativismo (feitas por filósofos analíticos em geral, como também por Popper e seus adeptos) e com o irracionalismo/subjetivismo (cf. Scheffler, 1967). A interpretação mais corrente da incomensurabilidade é a de que ela implicaria a quebra de comunicação entre os cientistas. Davidson (1974) procurou refutar tal tese, argumentando que ela seria tributária de uma ideia equivocada; a saber, a de esquema conceitual. Não existiria o mundo lá fora e, separadamente, as teorias que o descrevem. Por seu turno, Putnam (1992) ten-

9 Apesar de ter abandonado a analogia da mutação em prol da especiação evolucionária, Sankey (2000) chama a atenção para o fato de Kuhn ter, a despeito de seu intento contrário, saído de um relativismo conceitual inicial em direção a um relativismo de tipo ontológico. Mais recentemente, tentando ainda dar cabo dos problemas epistemológicos decorrentes da incomensurabilidade, Sankey (2009) propõe duas distinções: uma entre formas semânticas e metodológicas de incomensurabilidade e outra entre duas fontes de incomensurabilidade semântica (variação de sentido e descontinuidade referencial). 
tou mostrar as contradições subjacentes à incomensurabilidade, alegando que seus defensores afirmam a incompatibilidade entre teorias distintas, mas logo em seguida passam a descrever minuciosamente os dois lados em querela, como se estivessem em um ponto arquimediano, incorrendo, portanto, em argumentos contraperformativos.

Além da alusão aos cinco valores epistêmicos operantes na escolha de teorias, Kuhn (2000) respondeu a esse tipo de crítica com o contra-argumento de que a incomensurabilidade não é sinônimo de ausência de comunicação. Ele alegou que o termo foi tomado emprestado da matemática, na qual significa comparações que não possuem uma medida comum. Isso não quer dizer que, nas mudanças científicas, as teorias conflitantes não possam ser equiparadas. Na verdade, Kuhn passou a defender o que ele denominou "incomensurabilidade local", isto é, durante as revoluções científicas alguns termos antigos possuem correspondência direta com os novos, embora outros, não. Formulação que parece conflitar diretamente com sua tese do holismo teórico, já aludida. Seja como for, essa é apenas uma das estratégias utilizadas por Kuhn com o fito de dar cabo das acusações de relativismo e irracionalismo dirigidas a ele. Subjacente a isso está, a meu ver, o fato de essa questão ter passado a ser tratada exclusivamente em termos linguísticos. Com o passar do tempo, Kuhn discutiu a tese da incomensurabilidade cada vez mais no âmbito da filosofia analítica norte-americana. ${ }^{10}$

$\mathrm{O}$ fato de Kuhn ter passado a empregar o termo léxico em lugar de paradigma ou de exemplar, ou mesmo, de matriz disciplinar, é o maior indício de que ele passou a abordar a ciência, no geral, e não apenas a incomensurabilidade, em uma perspectiva meramente linguística. Basta lembrar suas recorrentes discussões acerca do problema da tradução - tão caro a filósofos do quilate de Quine - que o levaram a defender por fim o bilinguismo científico quando se trata da comunicação entre cientistas portadores de léxicos distintos. Isso parece ter fadado ao fracasso o intento de Kuhn de superar as implicações relativistas da tese. ${ }^{\mathbf{1 1}}$

É o que, por exemplo, pensa Mario Biagioli (1990), para quem a incomensurabilidade deve ser pensada em perspectiva mais ampla, envolvendo aspectos políticos, sociais e antropológicos. A rigor, a incomensurabilidade costuma ocorrer não apenas por razões linguísticas e conceituais, mas também por estratégias de consolidação de

10 Para alguns autores, esse movimento empobreceu a abordagem inicial de Kuhn, cuja marca era a interdisciplinaridade. Ou seja, ele abandonou suas interessantes análises de cunho histórico e sociológico, de modo a procurar se inteirar das questões referentes à filosofia da linguagem. Esse é, por exemplo, o argumento desenvolvido por Bird (2002) e por Mendonça e Videira (2007).

11 Chen (1997) aventou a tese de que o relativismo decorrente da incomensurabilidade pode ser superado se for adotado um conceito de racionalidade que envolva um papel importante para os instrumentos científicos, que são independentes da teoria, embora sejam importantes no estabelecimento de taxonomias lexicais. Em artigo recente, Chen (2010) propõe que se pense a incomensurabilidade (revoluções científicas) em termos da independência dos conceitos de processos em relação aos conceitos de objetos. 
novos grupos científicos. Mais do que tentar convencer grupos oponentes com léxicos diferentes, os cientistas costumam lutar pela alteração das hierarquias disciplinares, bem como pela consolidação de suas identidades socioprofissionais. Malgrado o avanço da perspectiva de Biagioli em relação à concepção redutora de Kuhn, o fato é que ele também ainda circunscreve sua análise ao âmbito exclusivo da atividade científica. De fato, mesmo se referindo a fatores políticos e sociais, Biagioli delimita a atuação destes no interior dos grupos científicos. Em outras palavras, ele não aborda a ciência em sua relação com a sociedade entendida em sentido mais amplo. A fim de que possamos perceber mais claramente a questão da relação entre ciência e sociedade subjacente à obra de Kuhn, faz-se mister reavaliar a forma como ele abordou as relações entre a história da ciência e a filosofia da ciência. Aqui, nossa análise será em grande medida tributária das ideias defendidas por Fuller.

\section{A verdade sobre a "DUPla verdade”}

Apesar de ter advogado a tese segundo a qual a história da ciência e a filosofia da ciência são disciplinas autônomas e, ao mesmo tempo, complementares, Kuhn não conseguiu propor uma relação frutífera entre elas.

Brendan Larvor (2003) argumenta que Kuhn desconhecia o suporte filosófico de seus heróis historicistas (especialmente, Koyré e Butterfield), o que explicaria a confusão que ele fez entre os preceitos do historicismo e princípios a-históricos, no sentido de ter recorrido à história da ciência por meio de esquemas preconcebidos.

Por essa razão, segundo Larvor (2003), as teses de Kuhn devem ser tomadas mais como compromissos metodológicos implausíveis do que como conclusões históricofilosóficas. Independentemente da crítica de Larvor, o que me interessa é destacar a indesejada relação assimétrica com a qual Kuhn contribuiu notoriamente, a qual se mostra patente neste trecho.

Embora pense que a atual filosofia da ciência não tem muita importância para o historiador da ciência, creio profundamente que a maior parte do que se escreve sobre a filosofia da ciência poderia ser melhorado se a história desempenhasse um papel mais importante na sua preparação (Kuhn, 1989, p. 39).

É importante ressalvar que o tipo de história da ciência à qual Kuhn se refere é aquela denominada internalista. Apesar de reconhecer a influência de fatores externos (interesses sociais) sobre a atividade científica, Kuhn sustenta a tese de que a ciência madura (ciência normal) é relativamente indene. Desse modo, em certo sentido, não 
deixam de ser indevidas as acusações de irracionalismo e relativismo dirigidas a Kuhn, tendo em vista que ele defendeu a autonomia do progresso científico em relação às demandas advindas da sociedade afora. Para ser mais correto, Kuhn permaneceu em uma zona intermediária entre dois extremos. Portanto, dependendo do lugar de onde seja observado, ele parece ocupar a posição do lado extremo oposto: os filósofos tradicionais consideram a reconstrução histórica kuhniana demasiadamente externalista, enquanto os construtivistas sociais mais radicais acusam-no de ainda estar preso à historiografia internalista.

A despeito de ter elevado a história da ciência a uma posição de destaque e ter produzido trabalhos importantes nesse campo, a obra filosófica de Kuhn obteve um impacto infinitamente maior.

A rigor, como demonstra Stephen Brush (2000), Kuhn é praticamente ignorado nos trabalhos mais recentes de história da ciência, o que seria um mau sinal; pois, segundo Brush, a nova historiografia interpretou inadequadamente a máxima de Kuhn, segundo a qual o historiador deveria pôr de lado a ciência que ele conhece, como se não fosse necessário saber nada sobre qualquer ciência. O trabalho historiográfico de Kuhn mostraria que ele conhecia as ciências em questão, a ponto de poder "discutir" com os especialistas da área. Brush retrata Kuhn como um historiador preocupado com o conteúdo cognitivo da ciência. Apesar de reconhecer o valor das abordagens sociológicas, ele apresenta Kuhn como um historiador bem distante dos estudos sociais da ciência mais radicais. ${ }^{12}$

De todo modo, Brush não indica claramente as razões que explicariam a falta de influência visível de Kuhn sobre a história da ciência. Uma hipótese plausível, já aludida, mas que não testaremos aqui é que, enquanto na historiografia internalista tradicional, Kuhn é visto como excessivamente externalista, na nova historiografia, ele é acusado de internalismo extremado, ou seja, Kuhn se torna dispensável, para ambas as abordagens, em virtude de um suposto radicalismo.

O pressuposto principal da historiografia desenvolvida por Kuhn consistiu na recomendação de compreender as teorias ultrapassadas em seus próprios termos. ${ }^{\mathbf{1 3}}$

12 Robert Nola (2000) desenvolve um argumento equivalente, no qual afirma que Kuhn se distancia do programa forte no que tange à escolha de teorias - estas seriam decididas por intermédio de valores epistêmicos compartilhados. 13 Kuhn (1989, p. 15) fornece algumas regras metodológicas que teriam conotação hermenêutica: “(...) na leitura das obras de um pensador importante, procurar em primeiro lugar os absurdos aparentes no texto e perguntar a si mesmo como é que uma pessoa sensata os poderia ter escrito. Quando se tiver encontrado uma resposta, quando tais passagens ganham sentido, então talvez se descubra que passagens mais importantes, aquelas que previamente se julgaram compreendidas, mudaram de sentido". Há uma série de trabalhos que evidenciam os aspectos hermenêuticos na obra de Kuhn. O locus classicus é Rorty (1994). Além disso, está cada vez mais sedimentada a abordagem hermenêutica das ciências naturais, que visa a aproximar a filosofia pós-positivista da ciência e a filosofia continental, cujo representante principal é Patrick Heelan. 
Ou seja, as teorias atuais não deveriam ser vistas como o aprimoramento de erros das teorias obsoletas. Sendo assim, a historiografia dita whig cometeria um grave equívoco metodológico, na medida em que procura explicar o desenvolvimento da ciência em termos de progresso cumulativo. Inegavelmente, a posição antiwhig ou antipresentista trouxe benefícios importantes para a historiografia da ciência, notadamente para uma compreensão mais adequada, ou menos deturpada, dos episódios históricos. Não obstante, o antiwhiggismo exacerbado também impõe entraves para as abordagens que almejem abrir espaço para o papel a ser desempenhado pela normatividade. Sem contar a inconsistência quanto ao fato de defender uma ciência contextualizada e ao mesmo tempo querer saltar por cima do contexto científico no qual se está inserido (cf. Nickles, 1995; Tosh, 2006).

Do exposto, verifica-se que a filosofia da ciência deixou de desfrutar do privilégio de ser a única disciplina capaz de fornecer uma imagem acerca da atividade científica, uma vez que à história da ciência foi atribuído um status epistemológico e não mais uma função meramente ilustrativa. ${ }^{14}$ A bem da verdade, Kuhn contribuiu, notoriamente, para a constituição dos chamados History and Philosophy of Science (HPS) programas cujo principal intento é engendrar uma imagem mais adequada sobre a ciência por intermédio de uma abordagem complementar entre a história da ciência e a filosofia da ciência -, ${ }^{\mathbf{5}}$ complementaridade que ficou comprometida desde o início. Ademais, essa análise da ciência por meio de uma filosofia da ciência historicamente orientada, ou mais apropriadamente, de uma história filosoficamente orientada, também despertou, desde o início, severas críticas e até mesmo autocríticas. Cale mencionar que Kuhn (2000a; 200ob) procurou equacionar os problemas remanescentes desse tipo de orientação, sem conseguir, a nosso ver, obter sucesso.

Não seria despropositado afirmar que Kuhn passou aproximadamente trinta anos (desde a publicação de sua obra capital, $A$ estrutura até seu último trabalho em vida, na verdade, uma obra inacabada ainda inédita) procurando dar conta dos problemas provenientes da tentativa de descobrir princípios gerais e permanentes (tarefa filosófica) subjacentes a uma atividade marcada pela transformação (domínio da história). Talvez lhe tenha faltado, para que chegasse a bom termo, um conhecimento maior sobre a história da filosofia, por um lado, e um estofo maior atinente à filosofia da história, por outro.

14. Nunca é demais lembrar a tão citada passagem com a qual Kuhn abre $A$ estrutura, em que ele defende um papel epistemológico para a história da ciência: "Se a história fosse vista como um repositório para algo mais do que anedotas ou cronologias, poderia produzir uma transformação decisiva na imagem de ciência que atualmente nos domina" (1978 [1962], p. 19).

15 O espírito desse projeto foi exemplarmente captado por Lakatos em sua famosa paráfrase de Kant: "A filosofia da ciência sem a história da ciência é vazia; a história da ciência sem a filosofia da ciência é cega” (1987, p. 11). 
A despeito de os impasses apontados em diversos tipos de crítica, pode-se afirmar que essa perspectiva inaugurada nos anos de 1960 ainda persiste nos trabalhos de Larry Laudan, filósofo que ambicionou dar consistência à filosofia em clave histórica por intermédio de seu programa para testarteorias da mudança científica (testing-theoriesof-scientific-change-programme), cujo objetivo maior foi o de que a filosofia da ciência se assemelhasse à própria ciência, testando modelos de mudança científica a partir dos próprios dados históricos. ${ }^{16}$

Outro projeto menos conhecido, porém muito interessante e, simultaneamente, polêmico, que também procura irmanar a história da ciência e a filosofia da ciência, é o levado a cabo por Hasok Chang (1999). Seu escopo é que essas duas disciplinas juntas possam gerar conhecimento científico onde a própria ciência não mais o faz, uma vez que o progresso se dá ao preço do abandono de certos problemas em prol de outros; ou seja, HPS poderia ser a continuação da ciência por outros meios.

A despeito de os problemas aparentemente insolúveis suscitados pela abordagem filosófica da ciência historicamente orientada, e mais especificamente da descrição assimétrica sobre a relação entre a filosofia da ciência e a história da ciência feita por Kuhn, o fato é que poucos agora defendem a tese de que uma dessas disciplinas possa sozinha dar conta das questões referentes à ciência.

Em seu polêmico e estimulante livro sobre Kuhn, o autodenominado epistemólogo social Steve Fuller (2000) delineia um panorama bastante rico sobre o contexto político-social no qual o autor de $A$ estrutura das revoluções científicas estava inserido, sem pôr de lado, no entanto, o seu pensamento propriamente histórico-filosófico.

Segundo a sentença de Fuller, Kuhn compartilhava do fenômeno "elitista" que, remontando a Platão, perpassa a história do pensamento ocidental como um todo - da “dupla verdade". Não se trata, necessariamente, da crença de que a 'verdade' não é una, mas, sim, de que ela deve - ou pode - ser conhecida somente por alguns; o que significa dizer que existiria uma espécie de aristocracia espiritual. No caso específico de Kuhn, essa postura jamais foi explicitamente endossada. Na realidade, ela se caracterizou por tensão e ambiguidade constantes. De todo modo, o fato é que Kuhn defendeu a possibilidade de dois tipos de história frontalmente conflitantes - a narrada pelos próprios cientistas ou divulgadores da ciência e a contada pelos historiadores - poderem conviver harmoniosamente, embora somente as narrativas produzidas pelos his-

16 Uma crítica particularmente interessante do projeto de Laudan foi levada a cabo por Hans Radder (1997, p. 6389). Segundo esse autor, há equívocos comprometedores na abordagem pretensamente naturalista normativa de Laudan. Um deles é julgar que a história pode fornecer dados neutros; outro é pensar que modelos normativos, como o de Popper, podem ser desbancados pelos casos históricos. É como se Laudan não percebesse que os argumentos favoráveis ou contrários a certas normas metodológicas não são eles próprios empiricamente testáveis. 
toriadores fossem mais fidedignas à prática científica. Fuller coloca a questão em termos bem provocativos.

O desvio de Kuhn sobre a história dessa doutrina [dupla verdade] é que a "plebe" passa a ser a comunidade científica (e muitos de seus simpatizantes filosóficos), e a "elite", os historiadores. Coloque-se desse modo: antes de Kuhn, os defensores das verdades esotéricas escondiam-se da visão pública por medo de perseguição; depois de Kuhn, eles fazem piadas entre si diante de uma demonstração pública da autoridade científica. Olhe para a fileira de trás de qualquer palestra pública dada por um cientista proeminente. Você verá historiadores e sociólogos (e uns poucos filósofos iluminados dando uma boa risada) desconstruindo qualquer referência histórica autorizada que os cientistas façam. Nunca a luz foi tão alegremente escondida de tantos! (Fuller, 2000, p. 27, grifo do autor).

O final dessa passagem permite antever a crítica que Fuller dirige também aos estudos mais recentes sobre a ciência. Por ora, interessa-me chamar a atenção, como o faz Fuller, para o fato de Kuhn identificar os historiadores como membros de uma elite intelectual da qual ele faria parte. É óbvio que, bem ao seu estilo, Fuller adota a atitude de desmascaramento, podendo ser ele mesmo, por isso, alvo de um "desmascaramento" posterior. Seja como for, não se pode negar que Kuhn, como deixa transparecer em sua entrevista autobiográfica (2000), deu uma guinada para a história da ciência, não apenas por razões contingentes e fortuitas, mas porque a física da época não lhe permitia tratar das questões "filosóficas" de seu interesse. Mantendo o cuidado de atenuar seu tom incisivo, podemos concordar com Fuller que Kuhn, insatisfeito com a ciência de seu tempo, encontrou consolo no ofício de historiador. Sendo essa constatação verdadeira, uma questão parece impor-se. Por que Kuhn, uma vez que não se quis insurgir diretamente contra o tipo de ciência praticada por seus contemporâneos, ao menos não utilizou a própria história para alcançar esse objetivo?

Kuhn ocasionou uma liberação, embora involuntariamente, de questões fundamentais que haviam se tornado marginalizadas na filosofia da ciência. Não obstante esse mérito, ele não as tratou de forma franca e direta. Como Fuller (2000) afirma - na primeira parte de seu livro ele deixa isso patente por meio da reconstrução histórica Kuhn precisa ser compreendido como um produto da guerra fria, cuja repercussão sobre o mundo acadêmico também não tardou em se dar. Sem o saber, ele teria feito parte de um projeto arquitetado por James Conant, então presidente da Universidade de Harvard, de defender a autonomia da ciência perante a sociedade, uma vez que sua áurea de conhecimento desinteressado e humanitário fora ofuscada com a produção e fatídica utilização - da bomba atômica. O que Conant não esperava, muito menos 
Kuhn, é que $A$ estrutura fosse causar o efeito devastador de uma dinamite explodida em seu próprio solo, e não no do "inimigo".

Com uma impressionante erudição, Fuller reconstitui, em linhas gerais, porém não superficiais, o momento histórico no qual Kuhn emergiu. Ele transita entre os contextos sociopolítico, cultural e acadêmico do período com admirável competência. Além disso, demonstra conhecer como poucos o pensamento do seu biografado, sem deixar de emitir juízos de valor de forma aberta e contundente. Fuller percebe que Kuhn é uma figura central da filosofia da ciência dita pós-positivista e um precursor dos estudos sobre ciência que começaram a despontar ao final dos anos de 1970 .

Eu penso que, por essa razão, uma parte considerável de sua vasta produção acadêmica dedica-se à compreensão e avaliação do pensamento kuhniano. Precisando melhor, o grande alvo dos ataques de Fuller é Kuhn, não apenas o da letra, mas sobretudo o do espírito, porquanto seu espectro ainda rondaria pelos departamentos de filosofia, como também pelas unidades dos science studies, semeando a "amnésia histórica" e a "anemia normativa".

No que tange especificamente ao papel da história da ciência, Fuller chega à conclusão de que, apesar de Kuhn ter dado um passo adiante em relação à historiografia whig, a sua abordagem prig não é suficiente para produzir uma história da ciência apropriada (normativa), o que só ocorreria por meio de uma historiografia tory, que defende a ideia de que a história da ciência deve se prestar especialmente a redescobrir linhas de pesquisa que ficaram no limbo da história. Para alcançar sua meta, Fuller toma como inspiração ou como modelo um filósofo hodiernamente demodè: Karl Popper. ${ }^{17}$

Se a acusação de Fuller segundo a qual Kuhn comungava da doutrina da "dupla verdade" for procedente, torna-se patente que um de seus objetivos era a defesa da prática de uma ciência autônoma e "desinteressada", concebendo a física como a filosofia por meios mais seguros. Com efeito, ao se decepcionar com a física de partículas

17 Em "Kuhn vs Popper", o objetivo de Fuller (2003) consiste exatamente em, contrariamente à tendência atual na filosofia da ciência, tomar partido de Popper em oposição a Kuhn, exaltando o componente prescritivo da filosofia de Popper (cf. 1992). Segundo Fuller, Kuhn venceu a "luta pela alma da ciência" contra Popper, mas, no fundo, quem saiu perdendo foi a sociedade em sentido mais amplo, bem como a própria ciência. Eu ousaria dizer, seguindo o espírito do pensamento de Fuller, que a ciência perdeu a 'alma'. Aliás, a própria filosofia da ciência também teria perdido, uma vez reduzida a questões técnicas particulares: "Como muitos outros de minha geração, eu estive sob o fascínio de Kuhn. Mas, gradualmente, eu estranhei porque a aceitação de suas ideias que pareciam radicais resultou no entendimento tímido da ciência que nós encontramos hoje. A resposta, eu sugiro, reside na compreensão pobre que nós continuamos a ter das implicações sociais dos regimes alternativos da produção de conhecimento. Questionamentos importantes sobre a racionalidade e o progresso na ciência como um todo, tão característicos de Popper e de filósofos anteriores da ciência, foram substituídos por análises mais técnicas da relação entre evidência e inferências em campos particulares. As únicas questões remanescentes parecem ser se as 'técnicas' apropriadas são filosóficas ou sociológicas. Perdido está um discurso contínuo e de amplo alcance sobre a direção que deveria ser dada a uma forma de inquirição que poderia comandar assentimento universal" (Fuller, 2003, p. 4). 
e sua relação "comprometida" com a indústria e a defesa de seu país natal, Kuhn procurou abrigo na história da ciência, de modo a poder investigar questões mais "teóricas", próprias da ciência básica. Obviamente, dito nesses termos, tudo soa como se Kuhn fosse intelectualmente covarde; quiçá, na verdade, trata-se mais de embotamento de visão do que de fraqueza de caráter. Seja como for, o fato é que Kuhn, longe de ter tentado minar a autoridade cultural da ciência, quis, em vez disso, livrar a física (sua área profissional original) da influência de interesses externos. Tanto assim que ele procurou, sem sucesso, desvincular-se da imagem de relativismo e irracionalismo decalcada sobre o programa forte, como veremos a seguir.

\section{Os HERDEIRos DE KuHN: FRAQUEZA do PROGRAMA Forte?}

As ideias defendidas por Kuhn foram contundentemente rechaçadas pela tradição analítica, sob a alegação de que elas teriam implicações relativistas. Kuhn procurou rebater as críticas que lhe foram endereçadas, buscando mostrar, inclusive, que em muitos pontos seu pensamento assemelhava-se ao dos filósofos analíticos. Em contrapartida, os adeptos do programa forte saudaram-no como um dos inspiradores da nova sociologia do conhecimento científico, ao ter mostrado a primazia do caráter comunitário da ciência. Kuhn, por seu turno, não recebeu os elogios de bom grado, chegando mesmo a lamentar-se de que teria havido deturpação de seu pensamento. Em suma, podemos dizer que um dos projetos mais acalentados de Kuhn consistiu em, por um lado, aproximar-se de seus perseguidores e, por outro, afastar-se dos seguidores.

Que o programa forte seja tributário de Kuhn é algo facilmente depreendido das próprias obras constituidoras desse programa. Basta lembrar um dos trabalhos mais importantes, ou, pelo menos mais citados, de Barry Barnes (1982), um dos fundadores do programa forte. Não se deve supor, no entanto, dada essa marcante e reconhecida influência, que os defensores do programa forte concordem ipsis literis com as teses kuhnianas. Na realidade, eles acusam Kuhn de ainda estar preso à concepção mais tradicional, uma vez que ele relegaria, às vezes, os fatores sociais ao âmbito externo à ciência.

É inegável que Kuhn leu alguns dos trabalhos mais empíricos realizados pelos sociólogos da ciência mais afinados com o programa forte, tendo até mesmo elogiado, com algumas ressalvas, o artigo agora clássico do seu ex-orientando Paul Forman (1971), no qual o autor procura mostrar que as ideias do mundo social mais amplo - na Alemanha derrotada do pós-guerra, a noção de que os fatos possuem encadeamento causal perdera a razão de ser, o que teria possibilitado o triunfo da teoria quântica - exerceram um papel preponderante nas controvérsias científicas, especificamente na vitória da teoria quântica. Por outro lado, é pouco provável que Kuhn se tenha debruçado so- 
bre os trabalhos considerados fundantes do programa forte, apesar de citar algumas passagens amiúde referidas pelos comentadores. O que me conduz a essa desconfiança é o fato de ele repetir alguns clichês equivocados, passíveis de serem evitados, desde que haja uma leitura um pouco atenta dos textos. ${ }^{18}$

É verdade que Kuhn é ambíguo em sua avaliação do programa forte. Com efeito, ora ele reconhece o mérito das teses aventadas por David Bloor e seus colegas, ora os reprova como propagadores da concepção de que a ciência não é um discurso (válido) sobre o mundo. Essa dubiedade reflete-se, às vezes, em um mesmo parágrafo:

O programa forte e seus descendentes têm sido reiteradamente rejeitados como expressões descontroladas de hostilidade à autoridade em geral e à da ciência em particular. Por muitos anos, eu mesmo reagi, de alguma forma, desse modo. Mas eu agora penso que essa avaliação fácil ignora um desafio filosófico real. Existe uma linha contínua (ou um declive escorregadio) indo das observações iniciais inevitáveis que subjazem aos estudos microssociológicos até suas conclusões ainda inteiramente inaceitáveis. Muito do que não deveria ser abandonado foi aprendido no percurso dessa linha. Mas ainda não está claro como, sem abandonar essas licões, a linha pode ser desviada ou interrompida, e como suas conclusões inaceitáveis podem ser evitadas (Kuhn, 2000, p. 111).

Kuhn reconhece que o programa forte levanta questões filosóficas genuínas, porém, ao mesmo tempo, repudia os resultados extraídos a partir de certas premissas. Eu creio que ele tenha em mente, especialmente, duas suposições em relação a seus herdeiros: eles teriam chegado à conclusão de que a ciência é determinada meramente por interesses sociais e de que a superioridade epistêmica da ciência é uma questão de fundo político. Conquanto Kuhn possa estar correto, em certo sentido, em atribuir essas teses ao programa forte, não se deve conjecturar que seus membros queiram minar a autoridade cultural da ciência como tal. Este parece ser o receio maior de Kuhn: ele não deseja que a ciência perca o seu status, tampouco sua autonomia, ainda que não esteja completamente satisfeito com o rumo tomado por ela. Por essa razão, Kuhn procurou evitar ser identificado como alguém que teria lançado as bases para o programa forte desenvolver seu projeto de "desmistificação da ciência".

18 Na minha interpretação, os princípios de causalidade, imparcialidade, simetria e reflexividade são inspirados na historiografia anti-whig proposta por Kuhn e outros. Nesse sentido, Kuhn não deveria ter renegado o programa forte como ele o fez. Bloor, especialmente, não é um relativista ingênuo e irresponsável como algumas avaliações apressadas fizeram crer. Na verdade, ele foi vítima da mesma injustiça da qual Kuhn sofreu. Para reavaliações mais ponderadas do programa forte e da nova sociologia do conhecimento científico, tanto positivas quanto negativas, ver, por exemplo, Friedman (1998); Freedman (2005); Lewens (2005); Kochan (2008; 2010). 
Conquanto tenha sido apontado pelos membros do programa forte como uma fonte de inspiração, Kuhn amiúde procurou renegar o tipo de trabalho levado a cabo por David Bloor e Barry Barnes, entre outros. Pode-se dizer que Kuhn não se reconheceu como um kuhniano. Eu julgo que ele manteve uma relação crítica com a nova sociologia do conhecimento científico por pura falta de uma compreensão adequada. Ou seja, Kuhn cometeu o mesmo erro crasso do qual ele sempre alegou ter sido vítima: rotulou os membros do programa forte de relativistas muito rapidamente. Por trás disso está em jogo, no meu ponto de vista, o fato de Kuhn ter buscado, primordialmente, defender a autonomia e, sobretudo, a independência da ciência frente à sociedade. Erroneamente, ele supôs que o programa forte visava a relativizar tal autonomia e minar a autoridade cultural da ciência. Em contraste com a postura reativa de Kuhn, Feyerabend deu boas-vindas aos trabalhos produzidos pelos praticantes da chamada nova sociologia da ciência e, sobretudo, pelos representantes dos science studies (cf. Mendonça; Araújo \& Videira, 2010).

\section{Conclusão: EM BUSGA DE UM NOVO PARADIGMA}

Das várias questões suscitadas neste artigo, a partir de uma análise crítica das obras kuhnianas de referência, eu chego à conclusão de que Kuhn continua sendo importante, tanto por possibilitar que se tenha um "olhar histórico" sobre o desenvolvimento da filosofia da ciência (lembremo-nos de que ele determinou e, em alguma medida, ainda determina, a agenda de problemas filosóficos), quanto por ter revigorado, embora à própria revelia, o tema candente das relações entre os fatores racionais e os valores sociais atuando na prática científica. Destarte, torna-se urgente uma reavaliação do seu pensamento no interior da zona de fronteira entre a filosofia da ciência e os novos estudos empíricos da ciência, de modo a se poder avançar no pertinente debate atinente à interface ciência/sociedade.

No ano em que $A$ estrutura completa 50 anos de publicação, faz-se mais do que oportuno repensar seu impacto no interior da filosofia da ciência, bem como dos science studies. Em que pese os inegáveis avanços alcançados por ambos os campos, eu creio que não se extraiu ainda as consequências mais diretas das teses aventadas por Kuhn, a começar por uma problematização mais aprofundada da imbricação entre os aspectos epistemológico e axiológico da prática científica; tampouco se refletiu franca e abertamente sobre a relação entre ciência e sociedade, salvaguardadas as exceções que confirmam a regra. Em uma era de patente comoditização da ciência, não podemos mais nos esquivar de questões como a da responsabilidade social dos cientistas e do envol- 
vimento da ciência com valores genuinamente democráticos. Afinal, não se pode servir a dois senhores: ou a ciência resgasta a tradição moderna que leva em consideração, primordialmente, seu compromisso epistemológico e ontológico com a verdade (ainda que esta não possa mais ser concebida com "V" maiúsculo) sobre os fatos e sua responsabilidade ética com os valores sociais mais amplos, ou sucumbirá no atendimento às demandas mercadológicas de interesses meramente econômicos. Quiçá abordar esse tipo de questão a sério requeira a concretização de uma nova mudança de paradigma no interior da filosofia da ciência.@

Agradecimentos. Agradeço os valiosos comentários e sugestões do Prof. Dr. Antonio Augusto Passos Videira, que ajudou a tornar o conteúdo e a forma deste artigo mais claros e precisos do que em sua primeira versão. Agradeço as pertinentes críticas dos dois pareceristas da revista. Não obstante o reconhecimento de sua inestimável contribuição, as eventuais falhas que persistam deverão ser imputadas única e exclusivamente a minha responsabilidade.

\author{
André Luis de Oliveira Mendonça \\ Pós-doutorando do Instituto de Medicina Social, \\ Universidade Estadual do Rio de Janeiro, Brasil. \\ andre.o.mendonca@ibest.com.br
}

\begin{abstract}
In this article I analyze the thought of Thomas Kuhn in the light of the idea that his work has reopened discussions on the relationship between science and society. In fact, his work The structure of scientific revolutions, published in 1962, had an impact that left indelible marks on the debates about scientific practice. As a consequence, two side effects arose: One of them leading the way to extremely technical matters and, somehow, unproductive. The other intensified the discussion concerning the place that science has - or should have - in society. My main argument is that the second effect was originated unconsciously by Kuhn. In other words, Kuhn can be seen as the generator of an involuntary liberation, because, regardless of his wishes, he reopened discussion of the science/society relationship. Thus, he can be pointed to as the major source of inspiration for the strong program and, subsequently, for science studies. Therefore, it is important to reevaluate his main theses in order to cast light on issues related to the interaction between rational factors and social values:
\end{abstract}

KEYwORDS $\bullet$ Science. Society. Rational factors. Social values. Kuhn. Strong program. Science studies. 


\section{REFERÊNGIAS BIBLIOGRÁFICAS}

Barnes, B. T. S. Kuhn and social science. London: Macmillan, 1982.

Biagioli, M. The anthropology of incommensurability. Studies in History and Philosophy of Science, 21, 2, p. 183-209, 1990.

BIRD, A. Kuhn's wrong turning. Studies in History and Philosophy of Science, 33, 3, p. 44.3-63, 2002.

Brush, S. Thomas Kuhn as a historian of science. Science \& Education, 9, p. 39-58, 2000.

Chang, H. History and philosophy of science as a continuation of science by other means. Science \& Education, 8, p. 413-25, 1999 .

Chen, X. Thomas Kuhn's latest notion of incommensurability. Journal for General Philosophy of Science, 28,2, p. $257-73,1997$.

. A different kind of revolutionary change: transformation from object to process concepts. Studies in History and Philosophy of Science, 41, p. 182-91, 2010.

Chibeni, S. \& Almeida, A. M. Investigando o desconhecido: filosofia da ciência e investigação de fenômenos "anômalos" na psiquiatria. Revista de Psiquiatria Clínica, 34, 1, p. 8-16, 2007.

Davidson, D. The very idea of a conceptual scheme. Proceedings \& Adresses of the American Philosofical Association, 47, 5, p. 20, 1974.

Deus, J. D. (Org.). A crítica da ciência. Rio de Janeiro: Jorge Zahar, 1979.

Doppetr, G. Kuhn's epistemological relativism: an interpretation and defense. Inquiry, 21, 1, p. 33-86, 1978.

Feyerabend, P. Consolando o especialista. In: Lakatos, I. \& Musgrave, A. (Org.). A crítica e o desenvolvimento do conhecimento. São Paulo: Cultrix/Edusp, 1979. p. 244-84.

Forman, P. Weimar culture, causality, and quantum theory: 1918-1927. Historical Studies in the Physical Sciences, 3, 1, p. 1-115, 1971 .

FReEdman, K. Naturalized epistemology, or what the strong program can't explain. Studies in History and Philosophy of Science, 36, p. 135-4,8, 2005.

Friedman, M. On the sociology of scientific knowledge and its philosofical agenda. Studies in History and Philosophy of Science, 29, 2, p. 239-71, 1998.

Reconsidering logical positivism. Cambridge: Cambridge University Press, 1999.

A parting of ways: Carnap, Cassirer, and Heidegger. Chicago: Open Court Press, 2000.

Fuller, S. Thomas Kuhn: a philosophical history for our times. Chicago: University of Chicago Press, 2000. . Kuhn vs Popper: the struggle for the soul of science. Cambridge, UK: Icon, 2003.

Habermas, J. Pensamento pós-metafísico: estudos filosóficos. Tradução F. B. Siebeneichler. 2 ed. São Paulo: Tempo Brasileiro, 2002 .

Kochan, J. Realism, reliabilism, and the "strong program" in the sociology of scientific knowledge. International Studies in the Philosophy of Science, 22, 1, p. 21-38, 2008.

. Contrastive explanation and the 'strong program' in the sociology of scientific knowledge. Social Studies of Science, 4, 0, 1, p. 127-44, 2010.

Kunn, T. S. A estrutura das revoluções científicas. 2. ed. São Paulo: Perspectiva, $197^{8 .}$ A função do dogma na investigação científica. In: Deus, J. D. (Org.). A crítica da ciência. Rio de Janeiro: Jorge Zahar, 1979. p. 53-80.

. A tensão essencial. Lisboa: Edições 7̧0, 1989.

. The road since structure: philosophical essays, 1970-1993, with an autobiographical interview. Chicago: University of Chicago Press, 2000.

. Possible worlds in history of science. In: The road since structure: philosophical essays, 19701993, with an autobiographical interview. Chicago: University of Chicago Press, 200oa. cap. 3, p. 77-114. 


\section{O legado de Thomas Kuhn após Ginquenta anos}

Kunn, T. S. The trouble with the historical philosophy of science. In:__. The road since structure: philosophical essays, 1970-1993, with an autobiographical interview. Chicago: University of Chicago Press, 200ob. cap. 5, p. 133-51.

Lacey, H. Valores e atividade científica 1. 2 ed. São Paulo: Associação Filosófica Scientiae Studia/Editora $34,2008$.

.Valores e atividade científica 2. São Paulo: Associação Filosófica Scientiae Studia/Editora 34, 2010.

LaKatos, I. O falseamento e a metodologia dos programas de pesquisa científica. In: Lakatos, I. \& Musgrave, A. (Org.). A crítica e o desenvolvimento do conhecimento. São Paulo: Cultrix/Edusp, 1979. p. 109-24.3. . História da ciência e suas reconstruções racionais. Lisboa: Edições 7๐o, 1987.

Lakatos, I. \& Musgrave, A. (Org.). A crítica e o desenvolvimento do conhecimento. São Paulo: Cultrix/Edusp, 1979.

Larvor, B. Why did Kuhn's SSR cause a fuss? Studies in History and Philosophy of Science, 34, p. 369-9o, 2003.

Lewens, T. Realism and the strong program. British Journal for the Philosophy of Science, 56, p. 559-77, 2005 .

Mastermann, M. A natureza do paradigma. In: Lakatos, I. \& Musgrave, A. (Org.). A crítica e o desenvolvimento do conhecimento. São Paulo: Cultrix/Edusp, 1979. p. 77-80.

Mello Filho, D. A epidemiologia, os valores e o significado de paradigma. Cadernos de Saúde Pública do Rio de Janeiro, 13, 4, p. 761-6, 1997 .

MendonçA, A. O progresso científico segundo Thomas Kuhn: especialização e incomensurabilidade. Rio de Janeiro, 2003. Dissertação (Mestrado em Filosofia). Universidade do Estado do Rio de Janeiro.

Mendonça, A. \& Videira, A.A. P. Progresso científico e incomensurabilidade em Thomas Kuhn. Scientiae Studia, 5, 2, p. 169-83, 2007 .

Mendonça, A.; Araújo, P. \& Videira, A. A. P. Primazia da democracia e autonomia da ciência: o pensamento de Feyerabend no contexto dos science studies. Filosofia Unisinos, 11, 1, p. 44-61, 2010.

Мімнот, L. La mirada psicoanalítica: un análisis kuhniano del psicoanálisis de Freud. Córdoba: Brujas, 2003.

NickLEs, T. Philosophy of science and history of science. Osiris, 10, p. 139-63, 1995.

NolA, R. Saving Kuhn from the sociologists of science. Science \& Education, 9, p. 77-90, 2000.

Popper, K. Conjecturas e refutações. Brasília: Editora UnB, 1972.

. A ciência normal e seus perigos. In: Lakatos, I. \& Musgrave, A. (Org.). A crítica e o desenvolvimento do conhecimento. São Paulo: Cultrix/Edusp, 1979.p. 115-41.

Putnam, H. Razão, verdade e história. Lisboa: Publicações Dom Quixote, 1992.

RAdDer, H. Philosophy and history of science: beyond the kuhnian paradigm. Studies in History and Philosophy of Science, 28, 4, p. 633-55, 1997.

Rorty, R. A filosofia e o espelho da natureza. Rio de Janeiro: Relume-Dumará, 1994.

. Objetivismo, relativismo e verdade. Rio de Janeiro: Relume-Dumará, 1997.

Thomas Kuhn, as pedras e as leis da física. Cadernos de Tradução da F.F.C., 1, p. 21-42, 1998.

Rouse, J. Engaging science: how to understand its practices philosophically. Ithaca: Cornell University Press, 1996.

SANKEY, H. Kuhn's ontological relativism. Science \& Education, 9, p. 59-75, 2000.

. Scientific realism and the semantic incommensurability thesis. Studies in History and Philosophy of Science, 40, p. 196-202, 2009.

Scheffler, I. Science and subjectivity. New York: Bobbs-Merrill, 1967.

Sellars, W. Empiricism and the philosophy of mind. Cambridge: Harvard University Press, 1997.

SHAPERE, D. Reason and the search for knowledge: investigations in the philosophy of science. Dordrecht: Reidel Press, 1984 . 
Tosh, N. Science, truth and history, Part I. Historiography, relativism and the sociology of scientific knowledge. Studies in History and Philosophy of Science, 37, 4, p. 675-701, 2006.

Watkins, J. Contra a "ciência normal". In: Lakatos, I. \& Musgrave, A. (Org.). A crítica e o desenvolvimento do conhecimento. São Paulo: Cultrix/Edusp, 1979. p. 33-48.

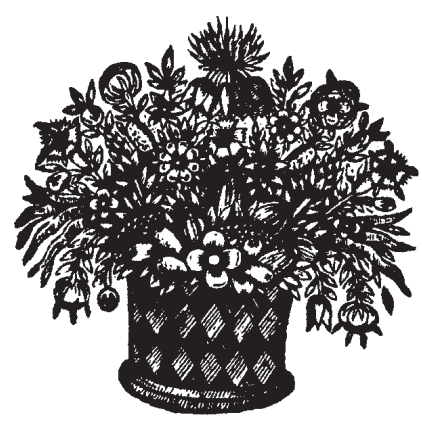

